\title{
The Influence of Concentrator Size, Reflective Material and Solar Irradiance on the Parabolic Dish Heat Transfer
}

\author{
Mohd. Ruddin Ab Ghani ${ }^{*}$, Rosnani Affandi', Chin Kim Gan', Siti Hajar Raman' and Jano Zanariah² \\ 'Faculty of Electrical Engineering, Universiti Teknikal Malaysia Melaka, Melaka, Malaysia; dpdruddin@utem.edu.my \\ ${ }^{2}$ Centre for Languages and Human Development, Universiti Teknikal Malaysia Melaka, Melaka, Malaysia
}

\begin{abstract}
Concentrating Solar Power (CSP) can meet the clean energy needs for power generation at a cost-competitive rate. Among the CSP technologies, Parabolic Dish (PD) has demonstrated the highest energy conversion efficiency. PD system produces electricity by using solar energy that is transferred from concentrator to receiver, to drive a Stirling engine and the generator. The concentrator in a PD system is used for focusing the solar radiation into the aperture of the receiver that is integrated in the Stirling engine. Stirling engine then converts the absorbed solar energy from the receiver into mechanical power by expanding the working gas in the cylinder. Then, the Stirling engine converts a linear motion into a rotary motion to turn the generator and produce electricity. This study is carried out to analyze the effect of the size, reflecting material and the solar radiation or Direct Normal Irradiance (DNI) to the rate of heat transfer from the concentrator to the receiver in the PD systems. For this purpose, a Matlab Simulink was used, in which the different rate of DNI in George Town, Penang Malaysia were taken into account. The study showed that the rate of heat transfer for the PD systems depended greatly on the size, reflecting material and the DNI of the area. These results are useful to help a better understanding of the relationship between size and reflecting material to the rate of heat transfer for a PD system under different DNI level.
\end{abstract}

Keywords: Concentrating Solar Power (CSP), Direct Normal Irradiance (DNI), Parabolic Dish (PD), Rate of Heat Transfer

\section{Introduction}

Concentrator in PD system is used for focusing the Direct Normal Irradiance (DNI) onto the receiver. Generally, in analyzing the operation of the PD concentrator, three parameters need to be considered. The parameters are: dish aperture size, reflectivity material and the irradiance ${ }^{1,2}$. Currently, the diameter range for $\mathrm{PD}$ concentrator that has been used in commercial plant is between 8-15 meters ${ }^{1}$. However, the size of PD concentrator depends on how much input power of the Power Conversion Unit (PCU) for the PD systems can handle. Furthermore, Mendoza ${ }^{3}$ argues that in order to transfer the heat to the receiver as well as to reach high operating temperature at the focal point, the geometric design for the concentrator has to be optimized.
Generally, PD concentrator consists of a mirror that typically was arranged in a parabolic shape. Meanwhile, the quality of a mirror concentrator is measured by its reflectance. Reflectance is a percentage of incident sunlight that can be reflected from the concentrator surface. Different materials can be used for reflective surface. However aluminum or silver are the most common materials that have been used since centuries as efficient mirrors concentrator in a PD system ${ }^{4-7}$.

Meanwhile, all CSP technologies including PD systems depend on the intensity of solar radiation ${ }^{8-10}$. Therefore, it can be said that the potential of a PD systems is largely determined by the solar radiation. According to Muhammad-Sukki et al. ${ }^{11}$, the world is estimated to receive approximately $1000 \mathrm{~W} / \mathrm{m}^{2}$ amount of solar irradiation in a day whereas PD systems require at least

${ }^{*}$ Author for correspondence 
1900-2000 kW/m²/year of Direct Normal Irradiance (DNI) to be economic ${ }^{11}$.

On the other hand, in terms of the technical feasibility; it is essential to ensure that the PD concentrator can transfer the heat to the receiver as well as generate operating temperatures at the focal point at least $250^{\circ} \mathrm{C}$ to as high as $1500^{\circ} \mathrm{C}^{12-15}$. Furthermore, previous research has revealed that the concentrator with a better reflectance has a significant role in helping the PD systems transfer the heat to the receiver, attain high temperature as well as higher efficiencies ${ }^{7,16,17}$. Therefore, the purpose of this study is to provide a better understanding of the relationship between size and reflecting material to the rate of heat transfer for a PD system under different DNI level.

\section{Methodology}

This study used a simulation approach using Matlab Simulink. The study focused on the conversion of solar energy to the heat energy transfer from the concentrator to the receiver in a PD system. The study of this simulation will help to better understand, especially the system interactions among concentrator and receiver subsystems in the PD system. The schematic diagram of a PD system is shown in Figure 1.

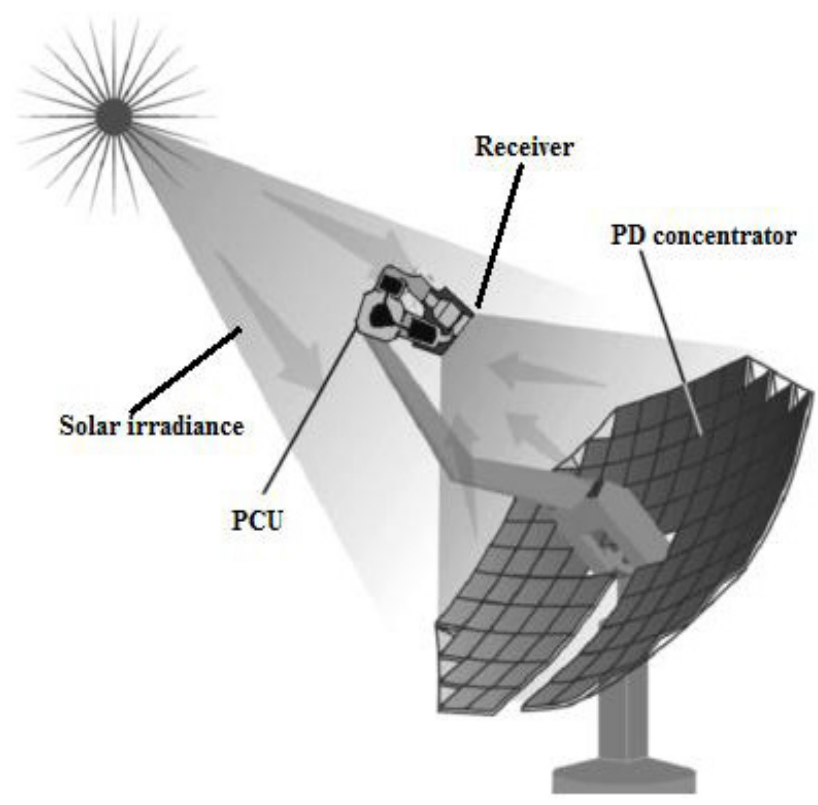

Figure 1. Schematic diagram of a PD system ${ }^{18}$.

\subsection{The Parameters Involved in the Heat Transfer from the Concentrator to the Receiver}

In a PD system, the solar radiation that is focused to the concentrator will produce heat from the concentration process. The heat then will be used for the energy conversion process. The rate of heat transfer from the concentrator to the receiver can be approximated by using an equation:

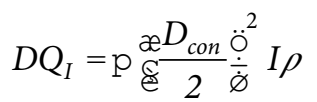

$\mathrm{D}_{\text {con }}$ is the size of the concentrator, $\rho$ is reflective of the concentrator and $I$ is the solar irradiance or DNI. Therefore, size, reflective material and the irradiance are the parameters that are important in determining the value of heat transfer from the concentrator to the receiver.

\subsubsection{Size of the Concentrator}

The different size of concentrator affects the rate of heat transfer to the receiver. $1 \mathrm{~kW}$ PD system was used for this study and sizes of 2.5 and 3.7 meters were recommended for the concentrator ${ }^{7}$. The different sizes were used to analyze the effect of the concentrator size to the rate of heat transfer from concentrator to the receiver of $1 \mathrm{~kW} \mathrm{PD}$ system.

\subsubsection{Reflective Material}

The different type or material that is used for the PD concentrator has different reflectivity ${ }^{2,19,20}$ (see Table 1). Generally, the concentrator is protected by either a protective sheet of glass or plastic ${ }^{21}$ and consequently, when the solar radiation passes through the concentrator, part of the solar radiation will be absorbed. The absorption of the solar radiation by the protective sheet can significantly reduce the solar energy that is transferred to the receiver.

Therefore, a clean and smooth reflecting surface is required for a PD concentrator for the dust particles could

Table 1. Reflectance of the Concentrator

\begin{tabular}{ll}
\hline Material & Reflectivity (\%) \\
\hline Stainless steel & 67 \\
Iron sheet & 87 \\
Aluminium & 92 \\
Silver & 96 \\
\hline
\end{tabular}


scatter away the solar radiation from the receiver. Apart from that, the solar radiation could be partly absorbed by a thin dust particles on the concentrator surface.

In the present PD designs, mirror reflectivity that has been used is in range of $91-95 \%{ }^{19}$. However, among the material used for the concentrator, silver is the preferred reflector material with aluminium second $\mathrm{d}^{1,7,16,22-24}$.

\subsubsection{Solar Irradiance or Direct Normal Irradiance (DNI)}

The input DNI data for George Town, Penang, Malaysia is used as the input data for the simulation ${ }^{10}$. The DNI data were downloaded from U.S Department of Energy website. Figure 2 shows the annual DNI data for George Town, Malaysia. From the data, the highest DNI was on 14 March with value of $943 \mathrm{~W} / \mathrm{m}^{2}$, Medium DNI was on 9 May with value of $466 \mathrm{~W} / \mathrm{m}^{2}$, while lowest DNI was on 4 August with value of $88 \mathrm{~W} / \mathrm{m}^{2}$.

Overall, the total highest irradiation was in February, followed by March, January, June, May, April, December, November, July and September. Meanwhile, the value for DNI in August and October throughout the month was below $200 \mathrm{~W} / \mathrm{m}^{2}$. Several days in January, August and December showed the DNI value of below $200 \mathrm{~W} / \mathrm{m}^{2}$.
The DNI value for 24 hours period for George Town, Penang, Malaysia is shown in Table 2. The lowest DNI value is shown in Figure 3, medium value in Figure 4 and the highest value in Figure 5. However, the rate of heat was taken and analyzed using 4 input DNI data in which the highest DNI is $943 \mathrm{~W} / \mathrm{m}^{2}$ for the simulation purpose. Two data during Medium DNI showed $466 \mathrm{~W} / \mathrm{m}^{2}$ and $200 \mathrm{~W} / \mathrm{m}^{2}$, while the lowest DNI is $88 \mathrm{~W} / \mathrm{m}^{2}$.

\section{Operational Framework}

Simulation for the rate of heat transfer from the concentrator to the receiver in a PD system requires a few external inputs such as: concentrator size, reflective material, and the solar irradiance or DNI. Refer to Figure 6.

\section{Simulation Result}

Tables 3-6 show the simulation result for the rate of heat transfer in a PD system by using 2 different sizes of concentrator, 4 different reflective materials and 4 different DNI data in George Town, Penang, Malaysia. From the table, the rate of heat transfer from the concentrator to the receiver for 2.5 meter concentrator during low DNI

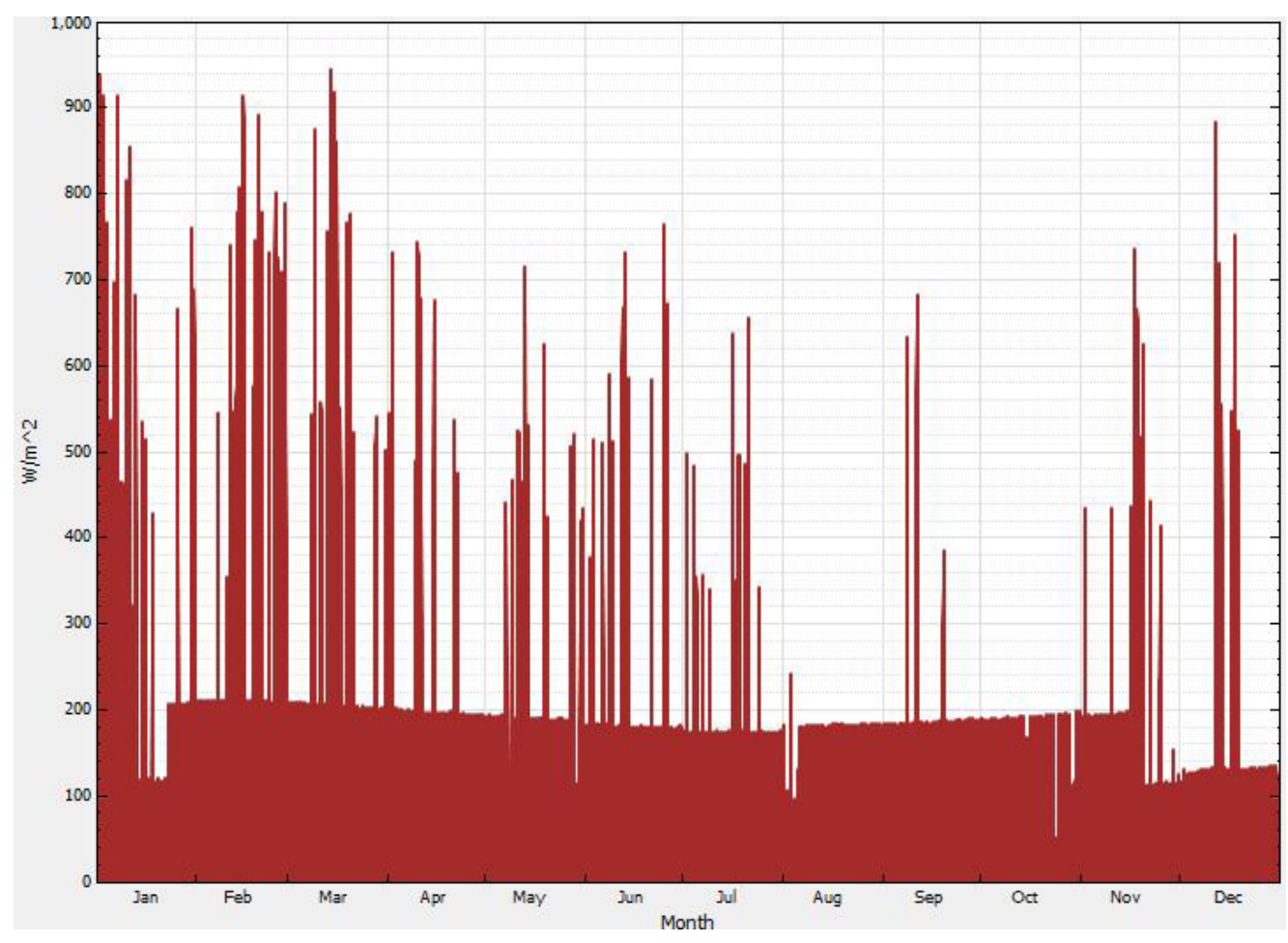

Figure 2. Annual DNI data for George Town, Penang, Malaysia Ease of Use. 
Table 2. DNI value in 24 hours data for George Town, Penang, Malaysia

\begin{tabular}{lccc}
\hline $\begin{array}{l}\text { TIME } \\
\text { (hour) }\end{array}$ & $\begin{array}{c}\text { Lowest DNI } \\
\left(\mathbf{W} / \mathbf{m}^{2}\right)\end{array}$ & $\begin{array}{c}\text { Medium DNI } \\
\left(\mathrm{W} / \mathbf{m}^{2}\right)\end{array}$ & $\begin{array}{c}\text { Highest DNI } \\
\left(\mathrm{W} / \mathbf{m}^{2}\right)\end{array}$ \\
\hline 1 & 0 & 0 & 0 \\
2 & 0 & 0 & 0 \\
3 & 0 & 0 & 0 \\
4 & 0 & 0 & 0 \\
5 & 0 & 0 & 0 \\
6 & 0 & 0 & 0 \\
7 & 0 & 0 & 0 \\
8 & 0 & 0 & 0 \\
9 & 38 & 140 & 273 \\
10 & 95 & 303 & 699 \\
11 & 87 & 466 & 886 \\
12 & 83 & 375 & 940 \\
13 & 88 & 286 & 886 \\
14 & 46 & 188 & 889 \\
15 & 87 & 190 & 887 \\
16 & 82 & 107 & 943 \\
17 & 85 & 90 & 880 \\
18 & 79 & 91 & 763 \\
19 & 6 & 21 & 468 \\
20 & 0 & 0 & 0 \\
21 & 0 & 0 & 0 \\
22 & 0 & 0 & 0 \\
23 & 0 & 0 & 0 \\
24 & 0 & 0 & 0 \\
\hline & & &
\end{tabular}

$\left(88 \mathrm{~W} / \mathrm{m}^{2}\right)$ was 320 to 450 watts; during DNI $200 \mathrm{~W} / \mathrm{m}^{2}$ was 620 to 850 watts; during medium DNI $\left(466 \mathrm{~W} / \mathrm{m}^{2}\right)$ was 1500 to 2300 watts and during highest DNI $(943 \mathrm{~W} / 2)$ was 3100 to 4900 watts.

Meanwhile, the rate of heat transfer from the concentrator to the receiver for 3.7 meter concentrator during low DNI $\left(88 \mathrm{~W} / \mathrm{m}^{2}\right)$ was 690 to 990 watts; during DNI $200 \mathrm{~W} / \mathrm{m}^{2}$ was 1400 to 1900 watts; during medium DNI $\left(466 \mathrm{~W} / \mathrm{m}^{2}\right) 3400$ to 4800 watts and during highest DNI $\left(943 \mathrm{~W} / \mathrm{m}^{2}\right)$ was 6800 to 9800 watts.

From the simulation result, the lowest value for the rate of heat transfer was 320 watts. The result was for 2.5 meter concentrator, using stainless steel as the reflective material and during lower DNI data at George Town, Penang. Meanwhile, the rate of heat transfer for 3.7 meter concentrator, for stainless steel reflector under low DNI level was 690 watts.

The highest value for the rate of heat transfer from the concentrator to the receiver in the simulation was 9800 watts. The value is for 3.7 meter concentrator, using silver as the reflective material and high DNI data which was $943 \mathrm{~W} / \mathrm{m}^{2}$. However, the highest value for the rate of heat transfer was 850 watts, for DNI $200 \mathrm{~W} / \mathrm{m}^{2}$, using 2.5 meter concentrator and silver as the reflective material. Meanwhile, the highest value for the rate of heat transfer for DNI $200 \mathrm{~W} / \mathrm{m}^{2}$, using 3.7 meter concentrator and silver as the reflective material was 1900 watts.

Based on the results, with 3.7 meter concentrator, DNI $200 \mathrm{~W} / \mathrm{m}^{2}$ is the lowest DNI input data that

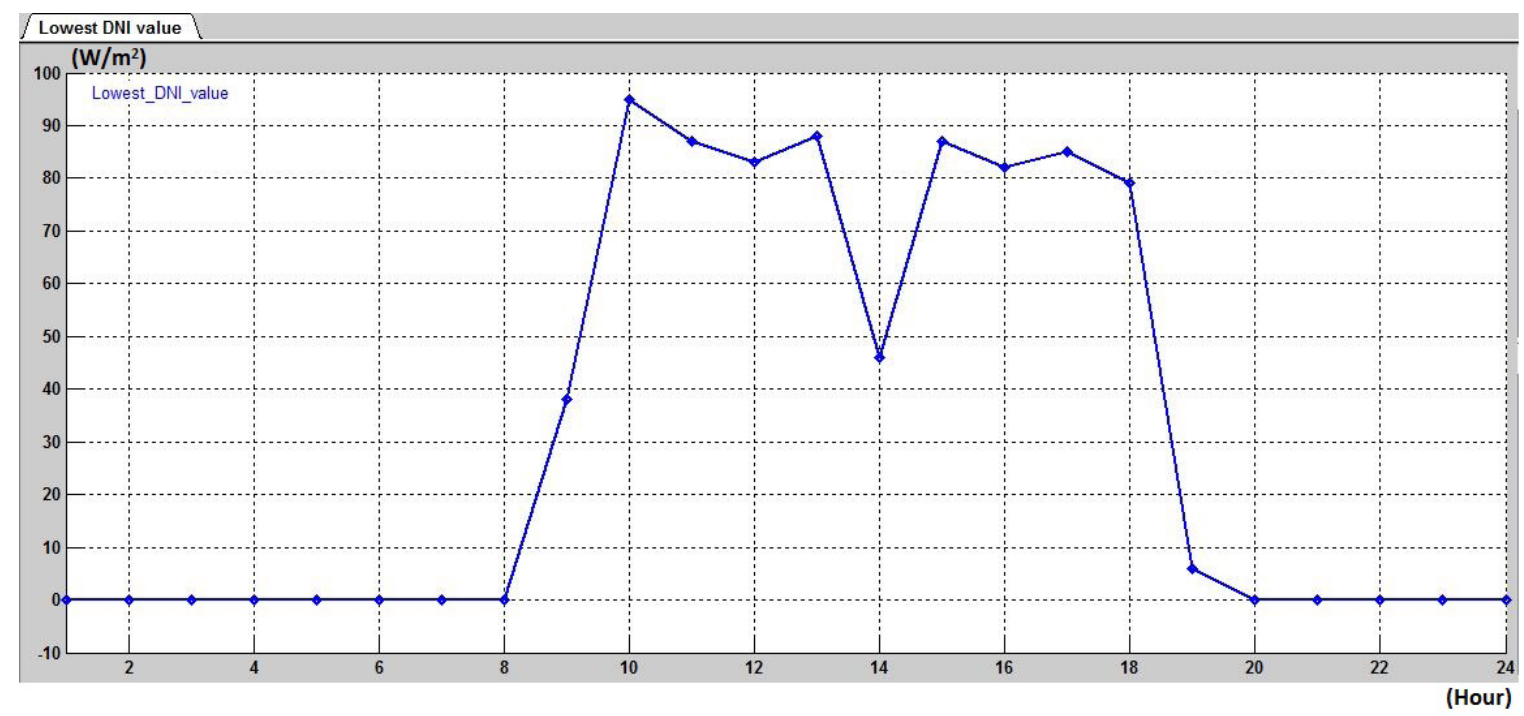

Figure 3. Graph for Time (Hour) versus irradiance (DNI) for the lowest DNI data in George Town, Penang, Malaysia. 


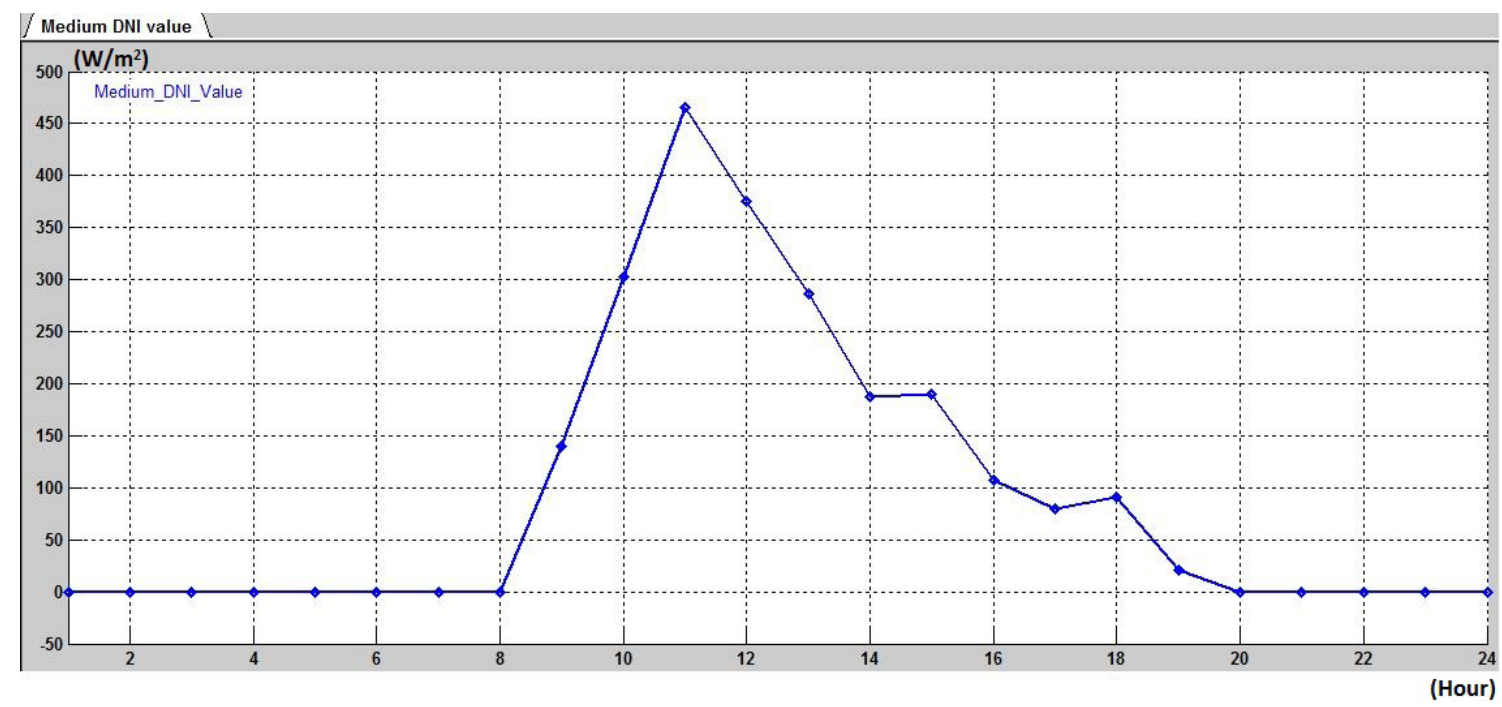

Figure 4. Graph for Time (Hour) versus irradiance (DNI) for medium DNI data in George Town, Penang, Malaysia.

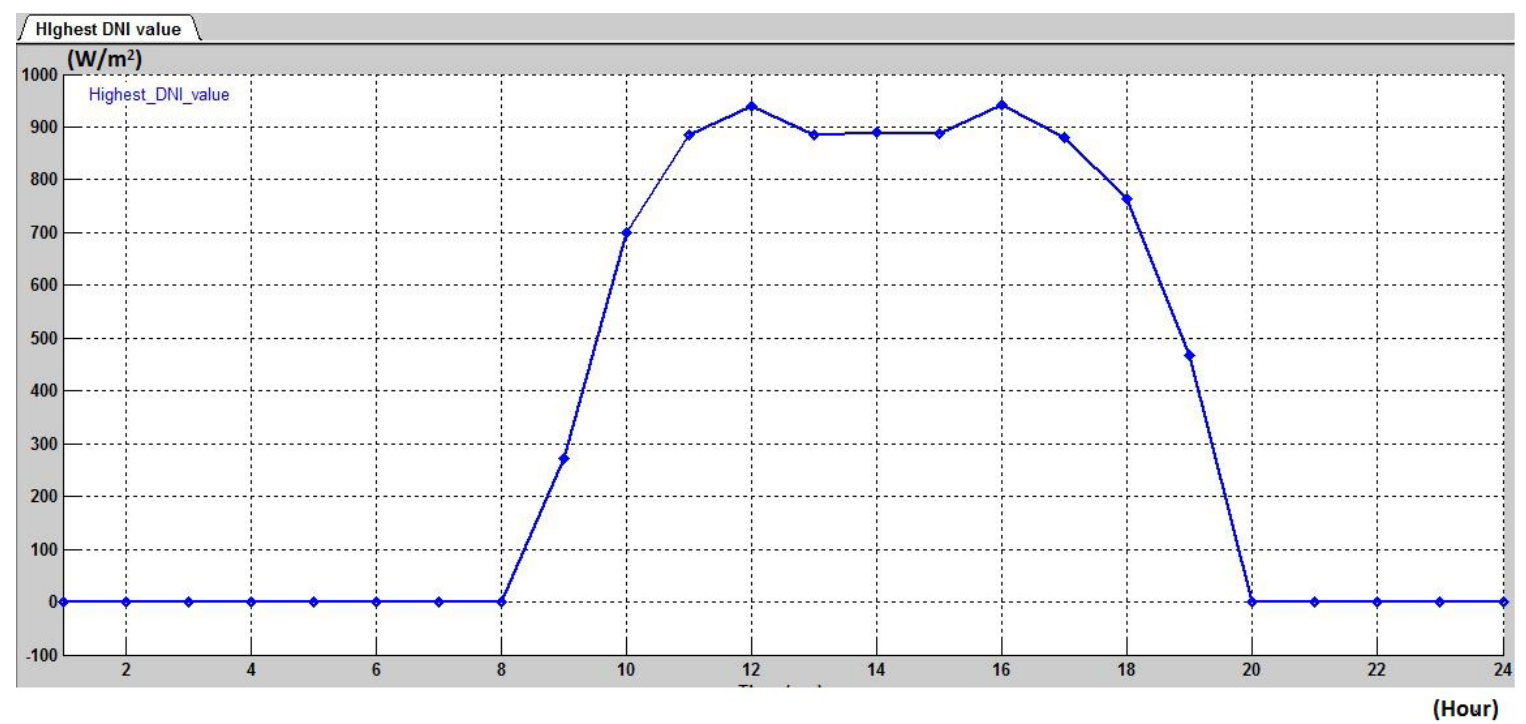

Figure 5. Graph for Time (Hour) versus irradiance (DNI) for highest DNI data in George Town, Penang, Malaysia.

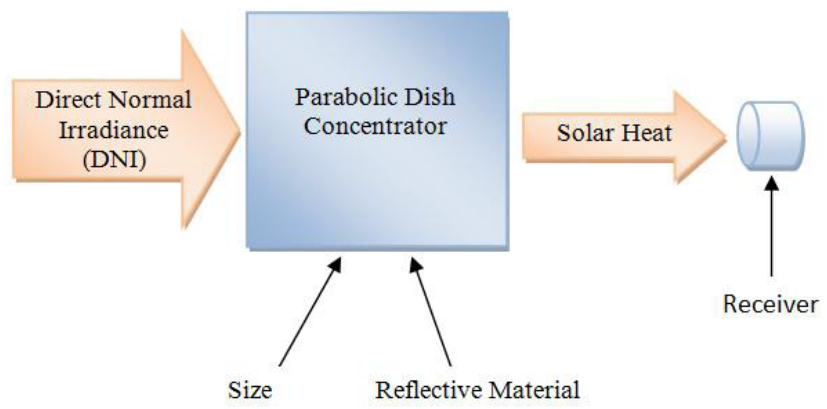

Figure 6. Scope of simulations for the heat transfer from concentrator to the receiver in $\mathrm{PD}$ system.
Table 3. Result for the rate of heat transfer in PD systems for lowest DNI level by using 2.5 and 3.7 meter concentrator and different type of reflective material

\begin{tabular}{|c|c|c|}
\hline \multirow{2}{*}{ Reflectivity } & \multicolumn{2}{|c|}{$\mathrm{DQ}_{\mathrm{I}}$ (watt) } \\
\hline & $\mathrm{D}_{\text {con }}=2.5$ meter & $\mathrm{D}_{\text {con }}=3.7$ meter \\
\hline 0.67 & 320 & 690 \\
\hline 0.87 & 400 & 890 \\
\hline 0.92 & 440 & 940 \\
\hline 0.96 & 450 & 990 \\
\hline
\end{tabular}


Table 4. Result for the rate of heat transfer in PD systems for $200 \mathrm{~W} / \mathrm{m}^{2} \mathrm{DNI}$ level by using 2.5 and 3.7 meter concentrator and different type of reflective material

\begin{tabular}{lcc}
\hline \multirow{2}{*}{ Reflectivity } & \multicolumn{2}{c}{$\mathrm{DQ}_{\mathrm{I}}$ (watt) } \\
\cline { 2 - 3 } & $\mathrm{D}_{\text {con }}=2.5$ meter & $\mathrm{D}_{\text {con }}=3.7$ meter \\
\hline 0.67 & 620 & 1400 \\
0.87 & 800 & 1700 \\
0.92 & 820 & 1800 \\
0.96 & 850 & 1900 \\
\hline
\end{tabular}

Table 5. Result for the rate of heat transfer in PD systems for medium DNI level by using 2.5 and 3.7 meter concentrator and different type of reflective material

\begin{tabular}{lcc}
\hline \multirow{2}{*}{ Reflectivity } & \multicolumn{2}{c}{ DQI (watt) } \\
\cline { 2 - 3 } & $\mathrm{D}_{\text {con }}=2.5$ meter & $\mathrm{D}_{\text {con }}=3.7$ meter \\
\hline 0.67 & 1500 & 3400 \\
0.87 & 2000 & 4400 \\
0.92 & 2100 & 4600 \\
0.96 & 2300 & 4800 \\
\hline
\end{tabular}

Table 6. Result for the rate of heat transfer in PD systems for highest DNI level by using 2.5 and 3.7 meter concentrator and different type of reflective material

\begin{tabular}{lcc}
\hline \multirow{2}{*}{ Reflectivity } & \multicolumn{2}{c}{$\mathrm{DQ}_{\mathrm{I}}$ (watt) } \\
\cline { 2 - 3 } & $\mathrm{D}_{\text {con }}=2.5$ meter & $\mathrm{D}_{\text {con }}=3.7$ meter \\
\hline 0.67 & 3100 & 6800 \\
0.87 & 4000 & 8800 \\
0.92 & 4300 & 9200 \\
0.96 & 4900 & 9800 \\
\hline
\end{tabular}

can produce more than $1 \mathrm{~kW}$ rate of heat transfer from the concentrator to the receiver. In which the value of the heat transfer from the concentrator to the receiver is 1400 watts for DNI $200 \mathrm{~W} / \mathrm{m}^{2}$ with 3.7 meter concentrator.

Moreover, the simulation results showed that the lowest value for the rate of heat transfer from the concentrator to the receiver which was below than $1 \mathrm{~kW}$ was during low DNI $\left(88 \mathrm{~W} / \mathrm{m}^{2}\right)$, for both sizes of concentrator and for all types of reflective material such as stainless steel, iron, aluminium and silver (See Figure 7).

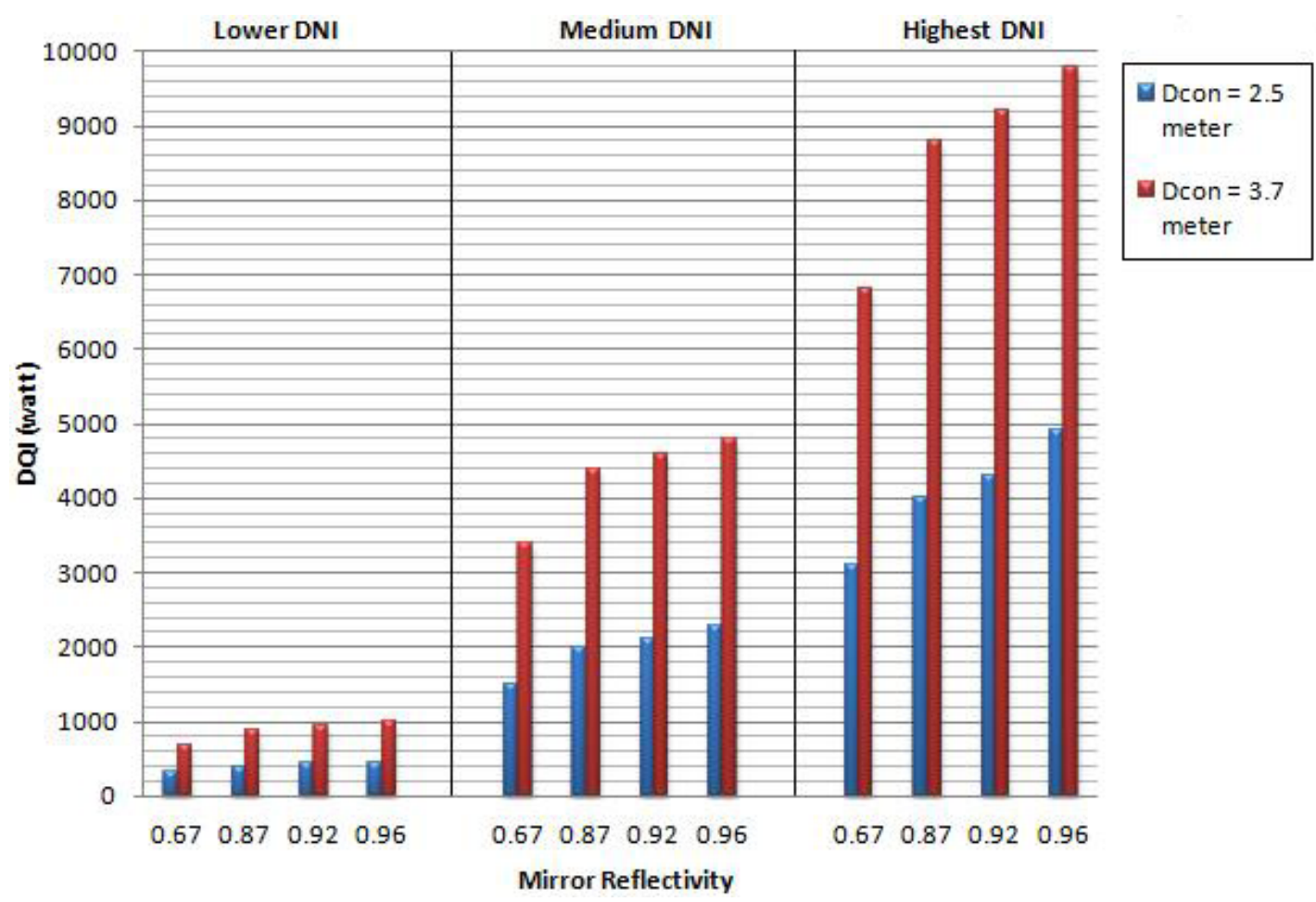

Figure 7. Rate of heat transfer for $\mathrm{D}_{\text {con }} 2.5$ and 3.7 meters based on the lowest, medium and highest DNI value with different type of mirror reflectivity. 


\section{Conclusion}

In conclusion, the increasing size of the concentrator, the better reflectance material used in concentrator and the higher the DNI input to the PD system, will significantly increase the rate of heat transfer from the concentrator to the receiver. These results are useful to help a better understanding of the relationship between size and reflecting material to the rate of heat transfer for a PD system under different DNI level.

\section{Acknowledgement}

The authors would like to gratefully acknowledge the funding support provided by the Ministry of Education Malaysia under the research grant No: FRGS/2/2013/ TK02/FKE/01/F00167.

\section{References}

1. Howard D, Harley RG . Modeling of Dish-Stirling Solar Thermal Power Generation. 2010 IEEE PES General Meeting; 2010 Jul 25-29; Minneapolis, Minnesota. IEEE; 2010. p. 1-7.

2. Sembiring M, Napitupulu F, Albar AF, El Husein MN. A stainless steel parabolic. ICEE. 2007; (1):45-9.

3. Mendoza S, Silva E, Almazan O, Guillen R. Modelling Generation Systems from using Solar Sterling Engines Parabolic Dishes (Solar Dish). WREF. 2012; 1-8.

4. Butel GP, Coughenour BM, Macleod HA, Kennedy CE, Olbert BH, Angel JRP. Second-Surface Silvered Glass Solar Mirrors of very High Reflectance. Proc SPIE 8108, High and Low Concentrator Systems for Solar Electric Applications VI; 2011.

5. Pitz-Paal R. High Temperature Solar Concentrators, Solar Energy Conversion and Photoenergy Systems. UNESCO, EOLSS Publishers; 2007.

6. Grandell L, Thorenz A. Silver supply risk analysis for the solar sector. Renew Energy. 2014; 69: 157-65.

7. Affandi R, Gan CK, Ab Ghani MR. Development of design parameter for the concentrator of Parabolic Dish (PD) based Concentrating Solar Power (CSP) under Malaysia environment. Journal of Applied Science and Agriculture. 2014 Jun 18; 1-6.

8. Machinda SK, Chowdhury S, Chowdhury SP. Concentrating Solar Thermal Power Technologies: A Review. 2011 Annual IEEE Indian Conference(INDICON); 2011 Dec 16-18; Hyderabad. IEEE Conference Publications; 2011. p. 1-6.

9. Affandi R, Ab Ghani MR, Gan CK, Jano Z. A Review of Concentrating Solar Power (CSP) in Malaysian environment. IJEAT. 2013; 3(2):378-82.
10. Affandi R, Gan CK, Ab Ghani MR. Performance Comparison for Parabolic Dish Concentrating Solar Power in High Level DNI Locations With George Town, Malaysia. $3^{\text {rd }}$ International Conference and Exhibitions on Sustainable Energy and Advanced Materials (ICE-SEAM 2013); 2013 Apr 4; Melaka, Malaysia.

11. Muhammad-Sukki F, Ramirez-Iniguez R, Mcmeekin SG, Steward BC, Clive B. Solar Concentrators. IJAS. 2010; $1(1): 1-15$.

12. Jayakumar P. Solar Energy, Resource Assessment Handbook. APCTT Of the United Nations- Economic and Social Commission for Asia and the Pacific (ESCAP); 2009 Sep.

13. Li X, Wang Z, Yu J. The Power Performance Experiment Of Dish-Stirling Solar Thermal Power System. Proceeding of ISES World Congress. 2009; 1858-62.

14. Dunn RI, Hearps PJ, Wright MN. Molten-Salt Power Towers: Newly Commercial Concentrating Solar Storage. Proc. IEEE. 2012; 100(2):504-15.

15. Balaya P, Cabeza L, Hollands T, Kondo M, Konseibo C, Meleshko V, Stein W, Tamaura Y, Xu H, Zilles R, Sokona Y, Seyboth K, Matschoss P, Kadner S, Zwickel T, Eickemeier P, Hansen G, Kingdom U. Direct Solar Energy. USA: Cambridge University Press; 2012.

16. Yousif BF, Al-Shalabi A, Rilling DG. On Integration of Mirror Collector and Stirling Engine for Solar Power System. Survival and Sustainability, Environmental Earth Sciences. 2011 Jan 4; 521-31.

17. Singh B, Tan L, Ezriq Z, Narayana PAA. Small Parabolic Solar Cooker for Rural Communities in Malaysia. 2012 IEEE International Conference on Power and Energy (PECon); 2012 Dec 2-5; Kota Kinabalu. IEEE; 2012. p. 116-20.

18. Li M, Dong J. Modeling and Simulation of Solar Dish-Stirling Systems. 2012 Asia-Pacific Power Energy Engineering Conference; 2012 Mar 27-29; Shanghai. IEEE; 2012. p. 1-7.

19. Nostell P, Roos A. Ageing of solar booster reflector materials. Sol Energy Mater Sol Cells. 1998; 54:235-46.

20. Peiyao Y, Laishun Y, Yuhua L, Qiuya N, Jianzhong N. Development of the experimental bench for a research on solar-dish. ISES Solar World Congress 2007: Solar Energy and Human Settlement. 2009; 1785-90.

21. Aker R. Investigation of feasibility for an inverter-controlled variable speed drive in a stirling CSP application. 2012.

22. Noor N, Muneer S. Concentrating Solar Power (CSP) and its Prospect in Bangladesh. 2009 1st International Conference on the Developments in Renewable Energy Technology (ICDRET); 2009 Dec 17-19; Dhaka. IEEE; 2009. p.1-5.

23. Fraser PR. Stirling Dish System Performance Prediction Model [M.Sc Thesis]. University of Wisconsin-Madison; 2008.

24. William PBD, Stine B. A Compedium of Solar/ Dish Stirling Technology.United States: 1994. 